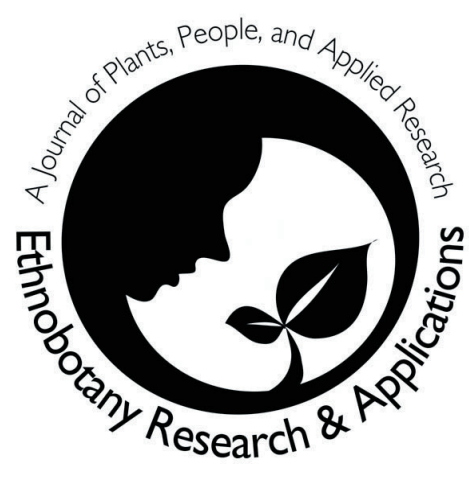

\title{
A Review of Recent Molecular Genetics Evidence for Sugarcane Evolution and Domestication
}

\author{
Laurent Grivet, C. Daniels, J.C. Glaszmann, and A. D'Hont
}

\begin{abstract}
In 1987, J. Daniels and B. T. Roach published an exhaustive multidisciplinary review of evidence permitting the domestication and the early evolution of sugarcane to be traced. We try here to synthesize the new data that have been produced since, and their contribution to the understanding of the global picture. It is now highly probable that sugarcane evolved from a specific lineage restricted to current genus Saccharum and independent from lineages that conducted to genera Miscanthus and Erianthus. The scenario established by E. W. Brandes in 1958 is very likely the right one: Noble cultivars (ie. Saccharum officinarum) arose from S. robustum in New Guinea. Humans then spread these cultigens over large distances. In mainland Asia, natural hybridization with $S$. spontaneum occurred, and gave rise to the North Indian ( $S$. barberi) and Chinese ( $S$. sinense) cultivars. Relationships between $S$. spontaneum and $S$. robustum in situations of sympatry are still not well understood.
\end{abstract}

\section{Introduction}

Sugarcane is an important crop plant cultivated throughout the world for its sugar-rich stalks. The Western world first learnt of the existence of this plant during Alexander the Great's conquests about two millennia ago. Since then historians have traced its extension towards North Africa, Europe and to the Americas through documentary evidence. What occurred before, that is, the evolutionary process that led to wild ancestors of sugarcane, and the domestication of those wild ancestors remained obscure until recently, and has been actively debated.

Like many tropical plants that are consumed for their vegetative organs, few remnants of sugarcane have been reported from archeological contexts. Moreover, distinction between wild and cultivated plant artifacts are problematic. Most information has therefore come from living wild and cultivated sugarcane plants and from written history and linguistic evidence for relatively recent events. In 1987, J. Daniels and B. T. Roach published a comprehensive review of hypotheses and arguments regarding sugarcane evolution and domestication, based on the available botanical, genetic and historical evidence. Since then, new data, particularly in the field of molecular genetics, have made it possible to reconsider evolution and domestication of sugarcane.

\section{State of the Art}

\section{Relevant germplasm}

From a practical point of view, sugarcane genetic resources can be divided into three groups: (1) traditional cultivars, (2) wild relatives, and (3) modern cultivars.

Traditional cultivars have almost disappeared from cultivation but remain important as progenitors of modern cultivars and as potential sources of traits for future breeding. Historically, they descend in straight line from

\section{Correspondence}

Laurent Grivet , J.C. Glaszmann \& A. D`Hont, CIRAD, UMR1096, TA40/03 Avenue Agropolis,34398 Montpellier cedex 5, FRANCE.

C. Daniels, Institute for the Study of Languages and Cultures of Asia and Africa, Tokyo University of Foreign Studies, 4-51-21 Nishigahara, Kita-ku, Tokyo 114-8580, JAPAN

Ethnobotany Research \& Applications 2: 9-17 (2004) 
primary domesticates. They are clones propagated by stem cuttings. They can be divided into two groups:

- The Noble cultivars. These generally have a chromosome number of $2 \mathrm{n}=80$ and brightly colored thick stalks, rich in sugar. They are still used in traditional agriculture, especially in Melanesia. The highest diversity is undeniably in the island of New Guinea. The term 'Noble' was given by the first Dutch breeders in Java. Those clones are formally designated by the species binomial S. officinarum $L$.

- The North Indian and Chinese cultivars. These generally have thinner stalks and leaves, flatter colors and lower sugar content than Nobles, a chromosome number $>80$ and a better adaptation to sub-tropical environments. They were formerly cultivated in mainland Asia, especially North India and South China, which are probably also where sugar-making industries were born. Nowadays, they are confined to germplasm collections. Five morpho-cytological groups have been described, Mungo, Saretha, Nargori, Sunnabile and Pansahi (Barber, 1922). The binomial $S$. barberi Jesw. usually refers to the first four groups, endemic to India. The fifth group is either included in S. barberi or referred to as $S$. sinense Roxb. It was common in China, and was introduced to India at the close of the 18th century.

A vegetable currently eaten in Melanesia is morphologically similar to sugarcane. It is cultivated for its edible aborted inflorescence and has no sugar content. Vernacular designations vary from island to island: It is for example 'naviso' in Vanuatu and 'pitpit' in New Guinea. We will use the name 'naviso' since 'pitpit' is also used to designate others plants, which may be confusing. The botanical designation of this cultigen is S. edule Hassk.

Wild plants related to traditional sugarcane cultivars and potentially included among their progenitors have been assembled into an informal taxonomical group, the 'Saccharum complex', first defined by Mukerjee (1957) and further extended by Daniels et al. (1975b). This includes:

- S. spontaneum L., a species presenting diverse morphologies and ecological adaptations. Stalks are usually thin and their sugar content is very low. S. spontaneum has a wide distribution range covering some Pacific islands, Melanesia, Tropical Asia, the Middle East and part of Africa (Panje and Babu, 1960). Chromosome complements vary between $2 n=40$ and $2 n=128$, the multiple of eight being more frequent.

- S. robustum Brandes and Jeswiet ex Grassl, a species presenting usually long, thick stalks with little or no sugar. Its distribution extends from Kalimantan (where it is rare), to Sulawesi, New Guinea and associated Melanesian islands. Chromosome number vary, but two cytotypes predominate $(2 n=60$ and $2 n=80)$.
- Species from the genera Erianthus, Miscanthus, Sclerostachya and Narenga. These genera have wide distribution ranges, from Himalaya to Melanesia, and for some, as far as the Pacific islands or Siberia. They generally have no sugar content and stalk morphology is variable depending on species. A particularly high concentration of species from these genera is encountered in the Northeast of the Indian sub-continent (Panje, 1953).

Modern cultivars have progressively replaced traditional cultivars during the 20th century. Most of the former were produced by artificial crosses between traditional cultivars and S. spontaneum clones, followed by several generations of clonal selection. The production of sugar has increased so much thanks to plant breeding, that traditional cultivars are now most often considered as relics and their use has become very limited as planting material and as progenitors in current selection programs. As modern cultivars have well-known and very recent origins, they are not useful for investigating the origins and domestication of sugarcane and are not considered further here.

\section{Scenarios for domestication}

Daniels and Roach (1987) reviewed hypotheses proposed in the last century concerning geography and process of sugarcane domestication. The most popular scenario has been the one developed by E. W. Brandes: Noble cultivars were domesticated from S. robustum in New Guinea and were then dispersed in the Pacific and mainland Asia during human migrations. In mainland Asia they hybridized with local S. spontaneum giving rise to North Indian and Chinese cultivars (Brandes, 1958).

The direct emergence of Noble cultivars from S. robustum is now generally accepted and it has been hypothesized that $S$. robustum was the result of complex introgressions between S. spontaneum and other genera, particularly Erianthus and Miscanthus (Daniels et al., 1978; Daniels and Roach, 1987). The emergence of Noble cultivars from a wild species other than $S$. robustum was considered a minor hypothesis. In this scenario, $S$. robustum populations may be secondary hybrids formed by crosses between Noble clones and wild related genera (Daniels and Roach, 1987).

Alternative scenarios for the emergence of the North Indian cultivars have been proposed. The first one is a direct selection from $S$. spontaneum, for at least some of the forms, particularly the Saretha group. The second one is hybridization between $S$. officinarum and a species of the genus Erianthus, most probably E. elephantinus, which is confined to the foothills of Assam and Nepal (Daniels and Roach, 1987). Parallel scenarios have been proposed for the emergence of Chinese cultivars, with either a de novo selection from unknown local wild species (Daniels and 


\section{Grivet et al. - A Review of Recent Molecular Genetics Evidence for Sugarcane Evolution and Domestication}

Daniels, 1993) or an alternative hybrid origin involving S. officinarum and Miscanthus sacchariflorus as wild progenitor, instead of S. spontaneum (Grassl, 1964).

Naviso is suspected to have emerged as a mutant within S. robustum or through interspecific hybridization between $S$. robustum and another species (Daniels and Roach, 1987).

\section{The Evolutionary Path Leading to Sugarcane}

Molecular data that clarify relationships between cultivated sugarcane and wild related species have been accumulating in the last ten years or so. The data generally do not support an evolutionary path through distant crosses involving representatives of several genera. Current living species of the genera Saccharum, Erianthus and Miscanthus are clearly distinct in analyzes of molecular variation in different sequence type and genome compartments. The nuclear genome has provided the greatest diversity of sequence types for analysis: low copy number sequences (Glaszmann et al., 1989; Lu et al., 1994), ribosomal RNA genes (Glaszmann et al., 1990) and repeated non-coding DNA (D'Hont et al., 1995). Mitochondrial and chloroplast genomes have also been analyzed (D'Hont et al., 1993). Most of those studies were conducted with few representatives of genera other than Saccharum. However, the Southern hybridization of repeated Alu-like and Satellite elements specific from the nuclear genome of Erianthus and Miscanthus did not show any trace of those genomes in any representative of Saccharum (Alix et al., 1998; Alix et al., 1999). Finally, an extensive survey of diversity in Erianthus was carried out with nuclear low copy-number DNA. This showed that Erianthus is probably monophyletic and highly divergent from genus Saccharum (Besse et al., 1997).

Recent genetic data support the existing view of genus Saccharum as a well-defined linage that include cultivated sugarcanes plus two wild species, $S$. spontaneum and $S$. robustum. This lineage diverged from other lineages, such as those leading to the genera Erianthus and Miscanthus, over a long course of evolution. The implication of this is that cultivated sugarcanes very likely emerged from wild Saccharum species, and secondary introgressions with other genera are not likely pathways.

This, however, does not mean that inter-generic hybridizations are impossible in the wild and may not account for some local peculiarities. Giant fencing clones of $S$. robustum from New Guinea highlands with high chromosome numbers, and clones of naviso ( $S$. edule) are candidates for derivation from inter-generic hybridization. This suggestion can be easily checked with molecular markers.
Restriction fragment analysis of the chloroplast genome (Sobral et al., 1994) as well as sequencing data for nuclear satellite DNA (Alix et al., 1998) and hybridization intensity signal with genus-specific Alu-like elements (Alix et al., 1999) indicate that Saccharum is likely more closely related to Miscanthus than to Erianthus.

The concept of a 'Saccharum complex' may have contributed to an overestimation of the contribution of other genera to the emergence of cultivated sugarcane. This concept was first developed based on geo-botanical considerations (Mukherjee, 1957; Daniels et al., 1975b) and later received the apparent support from analysis of leaf flavonoids (pigments). However morphological traits and flavonoids can be misleading when they are used as single diagnostic markers, especially in polyploid species. They provide few independent tests of genetic variation and their genetic determinants are unknown, although possibly polygenic and complexly regulated. For example, the flavone C-glycoside compound F13, which is assumed to be diagnostic for Erianthus, occasionally appeared in the progenies of crosses $S$. officinarum $\times$ S. spontaneum, although it was not transmitted by the parents (Williams et al., 1974). Such a marker should be used cautiously because introgression may not always be distinguishable from homoplasy or artifacts. Similar caution should be taken with morphological characters when they are used as diagnostic markers. In the past, morphology has often been misleading in the interpretation of the results of artificial inter-genera crosses, especially those involving Saccharum and Erianthus (D'Hont et al 1995; Piperidis et al., 2000).

\section{Origin of Noble Cultivars}

\section{The genus Saccharum is bipolar}

Two wild species are included in the genus Saccharum: S. spontaneum and $S$. robustum. Morphologically, $S$. robustum is distinguished from $S$. spontaneum by the "lack of rhizomes, larger inflorescence, smaller spickelet structures, greater thickness of stalk, and greater height" (Daniels and Roach, 1987). These differences are essentially quantitative. However, when allopatric samples are considered, S. spontaneum and S. robustum have been clearly differentiated in all molecular tests used so far. There is thus some genetic support for the taxonomic bipartition. Indeed, S. spontaneum collections from India and Southeast Asia (regions where S. robustum is absent), are strongly differentiated from $S$. robustum with nuclear low copy DNA revealed by RFLP (Lu et al, 1994) and mitochondrial DNA (D'Hont et al., 1993), and to a leather extend, with the differential hybridization intensity of a repeated and dispersed nuclear element, SoCIR1 (Alix et al., 1998) and ribosomal RNA (Glaszmann et al, 1990). Moreover, the basic chromosome numbers are different in $S$. spontaneum $(x=8)$ and $S$. robustum $(x=10)$. This was 
established by physical mapping, using fluorescent in situ hybridization (FISH) of two families of tandemly repeated ribosomal RNAs (D'Hont et al., 1998).

Data from leaf flavonoid are also interesting to consider here, even if they should be interpreted cautiously, because they have been more extensively used than any other type of genetic descriptor. We assembled scoring data that could be found in the literature for $S$. spontaneum and S. robustum (Daniels et al., 1975b; Daniels et al., 1978; Daniels et al., 1980; Daniels et al., 1989) and treated then together through a multi-variate analysis. By limiting the investigation to closely related material we expected to limit the effect of homoplasy. By analyzing the frequency of compounds in populations, instead of their presence vs absence in individuals, we expected to limit the effect of individual peculiarities (Figure 1). This permitted us to show that a bipolar structuring of wild Saccharum accessions is observed like that for other molecular descriptors. The case of population 'Kalimantan', a set of wild clones collected through the island of Kalimantan, is interesting to consider here because its classification in $S$. spontaneum or $S$. robustum has been debated (Daniels et al, 1989). It is grouped here in the $S$. spontaneum pole. This is in line with the cytoplasmic pattern for two of these clones (D'Hont et al., 1993) and this also fit with the initial description as "atypical S. spontaneum" by collectors in the field (Berding and Koike, 1980).

\section{Sympatric S. spontaneum and S. robustum}

Genetic distinctions between the two wild Saccharum species (S. spontaneum and S. robustum) are less clear in regions of sympatry, that is in the islands ranging from Borneo (Kalimantan) to New Britain. However, relevant data are still sparse. In New Guinea, field observations show that extreme types are still easily distinguished, but that variation in the two species overlap and some individuals present intermediate characteristics and are difficult to classify (Henty, 1969).

Recently, D'Hont et al. (1998) showed that S. spontaneum clones from New Guinea, with $2 n=80$ chromosomes, have a typical basic chromosome number of $x=8$, like S. spontaneum in other areas. However, they show just the same intensity of hybridization signal as S. robustum clones with the $S$. officinarum satellite element SoCIR1 (Alix et al., 1998). They appear more closely related to $S$. robustum than to any $S$. spontaneum clones with nuclear low copy DNA (Besse et al., 1997), and they transmit ' $n$ ' chromosomes when crossed with Noble cultivars, although a high proportion of ' $2 n$ ' gametes transmission is generally observed in crosses involving Noble cultivar and S. spontaneum (Daniels et al., 1975a).

Above data are heterogeneous but they suggest that at least some $S$. spontaneum populations, that are sympatric with S. robustum, are genetically closer to this species than allopatric populations. The simplest interpretation is that the sympatry between those two clearly differentiated species is recent and permits genetic exchanges. A more unlikely interpretation would be that the bipolar organization of wild Saccharum germplasm is a somewhat simplistic image due to biases in samples analyzed to date with markers and that the reality is more complex. An extensive molecular study of Saccharum germplasm is still needed to settle once and for all.

\section{Noble cultivars and wild Saccharum}

Several types of DNA sequence representing different genome compartments have been used to compare Noble cultivars and wild Saccharum accessions. In tests with mitochondrial genes, a single haplotype was detected among Noble clones (D'Hont et al. 1993). The same haplotype was the most frequent of two detected in $S$. robustum, and was different from all six haplotypes revealed in $S$. spontaneum.

With nuclear single copy DNA, Noble cultivars appear very close to $S$. robustum. Although the samples were distinct on the multi-variate representation, the average similarity between a Noble clone and a S. robustum clone is about the same as the average similarity between two S. robustum clones (Lu et al., 1994). The Noble clones used by Lu et al. (1994) appear representative, as can be judged from the comparison with additional clones from Indonesia and New Caledonia (Jannoo et al. 1999). In contrast, the $S$. robustum sample may not be fully representative, which may explain the small difference observed between Noble clones and S. robustum.

The basic chromosome number in Noble clones $(x=10)$ is the same as in $S$. robustum and is different in $S$. spontaneum, as was shown by physical mapping (D'Hont et al., 1998).

Leaf flavonoids were used to describe more clones than any other biochemical or molecular technique. With the cautious analyzes presented in Figure 1, they also show a close relationship between Noble clones and S. robustum. Thus multiple lines of molecular evidence support a direct descent of Noble clones from the wild species S. robustum. Direct selection from $S$. spontaneum in mainland Asia is excluded, as well as a descent via hybridization between S. spontaneum and other genera.

Some observations are not perfectly in line with the present conclusions, but are unlikely to alter them in any substantial way. A very small number of RFLP bands present in Noble clones were not detected in any tested wild Saccharum, and a sub-sample of these did occur in Erianthus or Miscanthus (Lu et al., 1994). This may indicate limited introgression from those genera. 


\section{Grivet et al. - A Review of Recent Molecular Genetics Evidence for Sugarcane Evolution and Domestication}

Figure 1. Saccharum germplam analyzed with flavonoid compounds. Sources of data are given in the text.

A. First plane of a Factorial Analysis performed on the frequency of 25 leaf flavonoid compounds in populations of $S$. spontaneum and S. robustum. Codes for species and populations are as follow (sample size is given in parenthesis): $\mathrm{R}$ is for S. robustum; with populations rl, for Red-leafed (4); w, for Wau-Bulolo (6); p, for Port-Moresby (6); rf, for Redfleshed (5); g, for Goroka (6); t, for Teboe-Salah (12). S is for S. spontaneum; with populations i, for India cytotype $2 n=40$ to 64 (24); i80, for India cytotype $2 n=80$ (9); a, for Southeast Asia (12); a80, for New Guinea 2n=80 (15); d, for diverse (4).

A

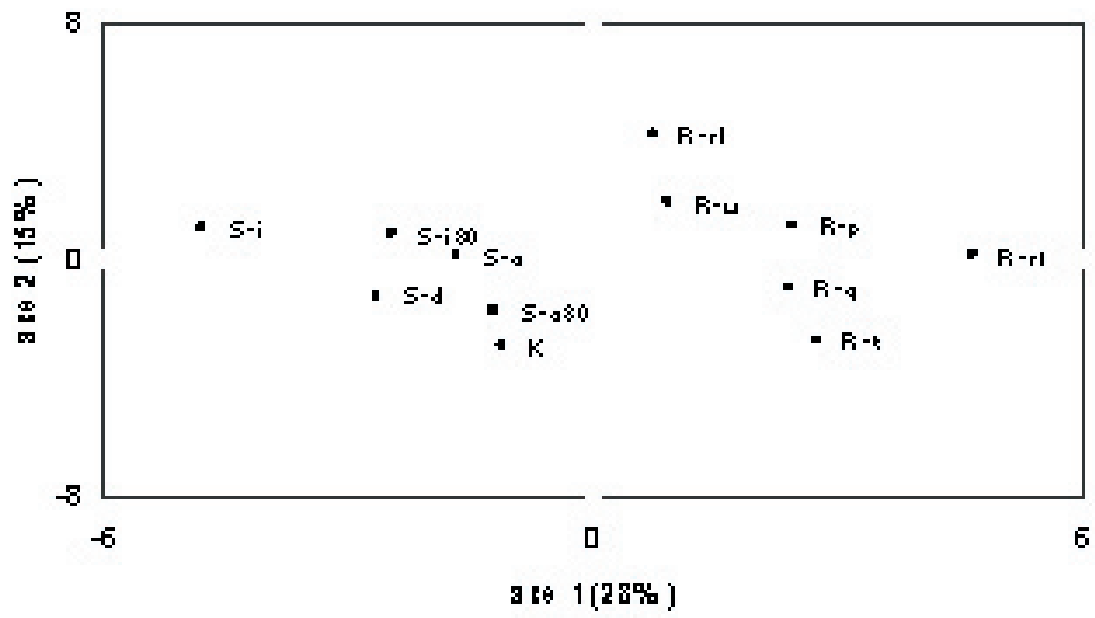

B. Same data with projection of Noble clones and Naviso (S. edule) populations. O is for Nobles clones with populations nc, for New Caledonia (4); ng, for New Guinea (10); h, for Hawaii (28); I, for Indonesia (12); g; for clones involved in genealogy of modern cultivars (20). $\mathrm{K}$ is for population Kalimantan (10). $\mathrm{E}$ is for Naviso (7).

B

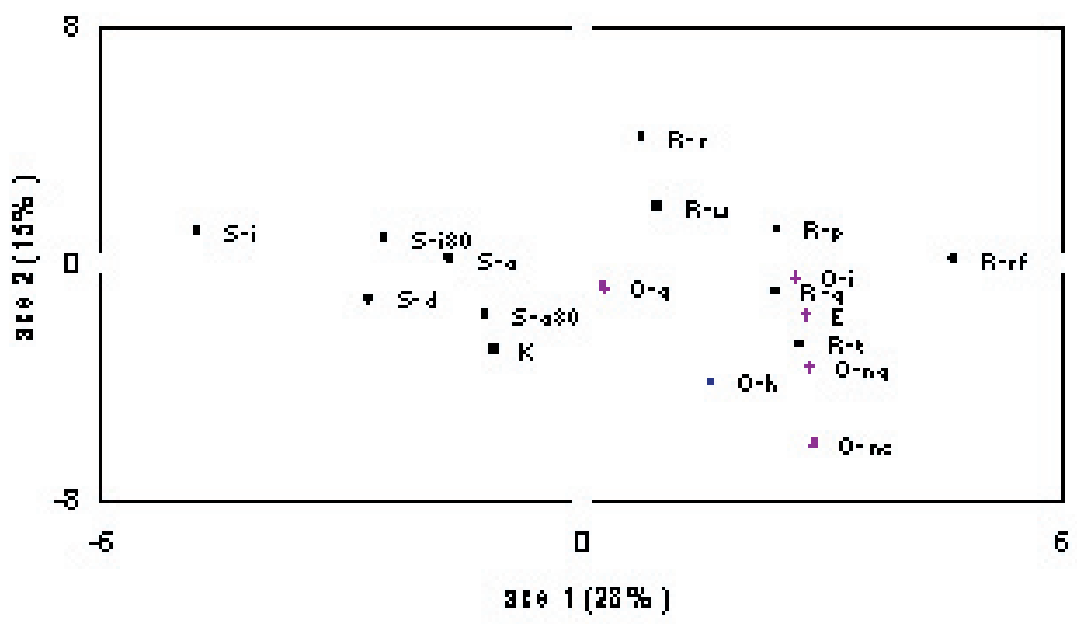


However, the proportion of demonstrated cases is so small that other explanations must also be considered: (1) the limited sampling of wild Saccharum representatives might have missed some RFLP bands present in Noble cultivars, and (2) co-migration of bands that correspond to different alleles in different taxa ie. homoplasy- is possible since these polyploid species display many RFLP bands.

\section{Origin of North Indian and Chinese Cultivars}

Molecular data clearly show that North Indian and Chinese cultivars are the result of interspecific hybridizations between representatives of the two Saccharum poles, S. spontaneum at one end, and the complex of wild and domesticated $S$. robustum and Noble clones at the other end. This is based mostly on data from low copy nuclear DNA and genomic in situ hybridization (GISH) (Lu et al., 1994; D'Hont et al., 2002). As the region where North Indian and Chinese cultivars are encountered is outside the natural distribution range of $S$. robustum, the scenario of Brandes provides the simplest explanation of the data: Noble cultivars were transported by man to mainland Asia where they hybridized with local $S$. spontaneum. It is likely that resulting clones are first-generation hybrids because no -or very few- interspecific chromosome exchanges have been detected with GISH, in contrast with modern cultivars (D'Hont et al., 1996). Owing to mitochondrial haplotypes, it is most likely that, in all cases, Noble clones acted as females and $S$. spontaneum clones acted as males in founding crosses (D'Hont et al., 1993).

Low copy nuclear RFLP data suggest that morphocytological groups among North Indian and Chinese cultivars each represent a set of somatic mutants derived from a single founding hybrid (D'Hont et al., 2002). The Pansahi cultivar group is not particularly distinct from the other groups in test with RFLPs. The North Indian and Chinese cultivars are thus all derived from a similar process that may have occurred repeatedly in different geographical regions.

These data exclude a direct emergence of North Indian and Chinese cultivars from S. spontaneum alone. Moreover, genetic contributions by either Erianthus or Miscanthus are very unlikely, as demonstrated by the Southern hybridization of Erianthus and Miscanthus genus-specific satellite and Alu-like repeated elements (Alix et al., 1998; Alix et al., 1999). Altogether, the recent studies indicate that the sugar-producing ability in cultivated sugarcane has a unique origin, the Noble clone, which was further transmitted to North Indian and Chinese cultivars and to the cultivars generated by modern breeding efforts. The evidence leaves little space for a hypothetical 'second path'.

\section{Origin of Naviso (S. edule)}

Few molecular data are available for tracing the origin of Naviso, alias S. edule. The mitochondria haplotype has been established for one clone and was identical to the more frequent of the two haplotypes detected in $S$. robustum. It was therefore identical to the haplotype of Noble clones (D'Hont et al., 1993). The chloroplast RFLP restriction pattern of another Naviso clone led to a similar conclusion (Sobral et al., 1994). Evidence for the nuclear genome is provided by flavonoids (Williams et al., 1974), which suggest that the domestication process for Naviso may have been like that for Noble clones (Figure 1). Clearly, this implies a direct selection from S. robustum alone. However, an interspecific origin, with $S$. robustum providing the female gamete, can still not be excluded at this stage.

\section{An Actual Scenario for Sugarcane Origin and Domestication}

The genus Saccharum is the sole lineage from which cultivated sugarcane emerged, and is distinct from the closely related genera, Erianthus and Miscanthus. As defined here, Saccharum encompasses two sister wild species, S. spontaneum and S. robustum.

The current geographical range of $S$. robustum is included in that of $S$. spontaneum. The two species have different ecological adaptation within the region of sympatry: $S$. robustum is a "fresh-water swamp grass favoring moving water" and $S$. spontaneum is adapted to better-drained soils and is a key component of coastal savannas, which are probably "fire-disclimax replacing forest after repeated gardening and burning" (Paijmans, 1976).

The sympatry could result from recent events linked to human activity, for example, direct transport (wild Saccharum species are used by people for many purposes) or a natural expansion in habitats disturbed by human activities ( $S$. spontaneum is considered as an invasive species in Asia and a growing number of other places). Indeed, S. robustum may only recently have extended to Kalimantan (Daniels and Roach, 1987), and $S$. spontaneum may only recently have extended to New Guinea (Berding and Koike, 1980). This would give late Pleistocene allopatric distributions for $S$. spontaneum and S. robustum. As the biogeography of South-East Asia and Melanesia is rich and complex with many islands and mountains, the speciation of Saccharum by isolation can easily be conceived. Moreover, as the Wallace line may have separated the putative ancestral distributions, so we can suggest a particular scenario for speciation. The Wallace line lies between two continental shelves, the Sunda shelf (mainland Southeast Asia, Java, Sumatra and Kalimantan) and the Sahul shelf (Australia, New Guinea and close islands). Each shelf was repeatedly unified into 


\section{Grivet et al. - A Review of Recent Molecular Genetics Evidence for Sugarcane Evolution and Domestication}

a single continental mainland during cyclic lowering of sea level that accompanied ice ages of quaternary era, but no earth bridge ever connected the two shelves. Ice age cycles gave opportunities to repeatedly establish genetic exchanges between separated populations on each shelf but exchanges between populations of the two shelves remained constantly limited during the three million years of the quaternary era. As a consequence, two sister species in the Saccharum lineage may have had the opportunity to differentiate in isolation after dispersal of a common ancestor thus giving rise to $S$. spontaneum on the Sunda shelf and $S$. robustum on the Sahul shelf. Recently, it has been becoming more and more obvious that quaternary climatic variation played an important role in the genetic structuring of populations and species that exist today (Hewitt, 2000).

In the island of New Guinea (Sahul), domestication of the wild local plants, i.e. S. robustum, would have led to the Noble cultivars. New Guinea is a well-established domestication center for several other important crops (Lebot, 1999). More than just a snack, the crop may have constituted a major source of carbohydrates for pigs and humans (Daniels and Daniels, 1993). The Noble clones could then reach Sunda and the Pacific islands in association with human migration or plant exchange. S. robustum also crossed the Wallace line to Kalimantan as a semi-domesticated plant used for medicine or fence building. In Sunda, the introduced Noble clones could hybridize with local wild S. spontaneum, producing feral interspecific hybrids. Spontaneous occurrences of such natural hybrids have been reported in Java (Stevenson, 1965) and in eastern India (Mukherjee, 1957).

Contact between cultigens and the wild species was probably frequent as $S$. spontaneum is an aggressive weed in sugarcane fields (Barber, 1920). In sub-tropical climates, hybrids proved to be better adapted to local conditions than Noble clones. Unlike the stalks of Noble clones, the stalks of hybrids could reach full maturity, enabling accumulation of saccharose, a crystallizable sugar. Adoption of hybrid cultivars was thus a prerequisite for the emergence of a sugar-making industry (Daniels, 1996). Hybridization and subsequent sugar manufacture may have occurred in one or several places in mainland Southeast Asia, probably in an area delimited by North India, Assam and North Myanmar, up to Yunnan in South China. This region encompasses all the known or suspected primary centers of sugar industry, S. spontaneum is present (Panje and Babu, 1960) and the latitudes are still favorable for flowering. The region was also crossed by a trade route since at least the first century A.D., if not earlier, giving many opportunities for circulation of plants and techniques.

In this scenario, S. spontaneum is a recent arrival in New Guinea. The plant dispersed easily in humanly disturbed habitats, which were frequent in lowlands. A single cytotype, $2 n=80$, has been founded in New Guinea. This is consistent with a recent founding effect. Introgression between $S$. robustum and $S$. spontaneum is likely to account for wild Saccharum populations reported to present intermediate characteristics.

\section{Conclusion}

Molecular markers are very helpful for understanding the domestication of crop plants. In the case of sugarcane, they have not suggested new evolutionary schemes but have helped to choose between previous scenarios that were based on plant and historical knowledge. There is now little doubt that sugarcane emerged within a specific Saccharum lineage, independent from the lineages of Erianthus and Miscanthus, and that the scenario established by Brandes to account for the origin of traditional cultivars is largely correct. Although samples have sometimes been small in studies so far, it is unlikely that an enlarged study will dramatically modify the picture. Now that robust molecular techniques are well established, the limiting factor for comprehensive understanding of plant domestication is often access to relevant germplasm.

The status of $S$. spontaneum in New Guinea and the relationships between wild $S$. spontaneum and $S$. robustum in the region of sympatry are still not completely clear. The scenario favored above presumes that introgression between the two Saccharum wild species does occur. However, other scenarios, more complex, may also account for current data. There is no doubt that new studies targeted toward the investigation of interactions between S. spontaneum, S. robustum and Noble cultivars in New Guinea, Sulawesi and Kalimantan will help to fully understand the dynamic process of sugarcane domestication.

\section{Acknowledgments}

We are very grateful to Dr Will McClatchey and all the organizers of the Building Bridge with Traditional Knowledge Summit meeting for making this event possible and for providing financial support to one of us to go to Hawai'i and present our work. We also acknowledge Dr Barbara Pickersgill who invited us to participate, as well as Dr Vincent Lebot of Cirad, Dept. of Agriculture, Vanuatu, Dr Mike Bourke of the Australian National University, Canberra, who were of great help in sharing field experience and giving access to relevant literature, and $\mathrm{Dr}$ Peter Matthews for useful comments on the manuscript.

\section{Literature Cited}

Alix, K., F.C. Baurens, F. Paulet, J.C. Glaszmann \& A. D'Hont. 1998. Isolation and characterization of a satellite 
DNA family in the Saccharum complex. Genome 41:854864.

Alix, K., F. Paulet, J.C. Glaszmann \& A. D'Hont. 1999. InterAlu like species-specific sequences in the Saccharum complex. Theoretical and Applied Genetics 6:962-968.

Barber, C.A. 1920. The origin of the sugar cane. The International Sugar Journal 22:249-251.

Barber, C.A. 1922. The classification of Indian Canes. The International Sugar Journal 24:18-20.

Berding, N. \& H. Koike. 1980. Germplasm conservation of the Saccharum complex: A collection from the Indonesian archipelago. Hawaiian Plantation Record 59:87-176.

Besse, P., C.L. Mclntyre \& N. Berding. 1997. Characterization of Erianthus sect. Ripidium and Saccharum germplasm (Andropogoneae Saccharinae) using RFLP markers. Euphytica 93:283-292.

Brandes, E.W. 1958. Origin, classification and characteristics. Pp. 1-35 in Sugarcane (Saccharum officinarum L.). Edited by E. Artschwager \& E.W. Brandes. U. S. Department of Agriculture Handbook 122.

Daniels, C. 1996. Biology and biological technology. Part III. Agro-industries and forestry. Pp. 129-172 in Science and Civilization in China. Volume 6. Edited by J. Needham. Cambridge University Press, Cambridge, United Kingdom.

Daniels, J. \& C. Daniels. 1993. Sugarcane in Prehistory. Archaeologia Oceania 28:1-7.

Daniels, J. \& B.T. Roach. 1987. Taxonomy and evolution. Pages 7-84 in Sugarcane Improvement through Breeding. Edited by D.J. Heinz. Elsevier Press, Amsterdam.

Daniels, J., P. Smith, N. Paton \& B. Roach. 1975a. 2n=80 S. spontaneum and the origin of sugarcane. Sugarcane Breeding Newsletter 35:19-20.

Daniels, J., P. Smith, N. Paton \& C.A. Williams. 1975b. The origin of the genus Saccharum. Sugarcane Breeding Newsletter 36:24-39.

Daniels, J., P. Smith, N. Paton \& B.T. Roach. 1978. The taxonomic status of Saccharum robustum Brandes \& Jeswiet ex Grassl. Proceedings of the International Society of Sugar Cane Technologists 16:71-84.

Daniels, J., N. Paton, P. Smith \& C.A. Williams. 1980. Further studies on leaf flavonoids as evolutionary indicators in Saccharum officinarum L. Proceedings of the International Society of Sugar Cane Technologists 17:1317-1335.
Daniels, J., N. Paton, P. Smith \& B.T. Roach. 1989. Further studies on the origin of sugar canes Saccharum officinarum L., S. barberi Jesw. and S. sinense Roxb. using flavonoid chemotaxonomic markers. Sugar cane, supplement, 7-15.

D'Hont, A., Y.H. Lu, P. Feldmann \& J.C. Glaszmann. 1993. Cytoplasmic diversity in sugar cane revealed by heterologous probes. Sugar Cane 1:12-15.

D'Hont, A., P. Rao, P. Feldmann, L. Grivet, N. Islam-Faridi, P. Taylor \& J.C. Glaszmann. 1995. Identification and characterisation of intergeneric hybrids, S. officinarum $\mathrm{x}$ Erianthus arundinaceus, with molecular markers and in situ hybridization. Theoretical and Applied Genetics 91:320-326.

D'Hont, A., L. Grivet, P. Feldmann, S. Rao, N. Berding, \& J.C. Glaszmann. 1996. Characterisation of the double genome structure of modern sugarcane cultivars (Saccharum spp.) by molecular cytogenetics. Molecular and General Genetics 250:405-413.

D’Hont, A., D. Ison, K. Alix, C. Roux \& J.C. Glaszmann. 1998. Determination of basic chromosome numbers in the genus Saccharum by physical mapping of ribosomal RNA genes. Genome 41:221-225.

D'Hont, A., F. Paulet \& J.C. Glaszmann. 2002. Oligoclonal interspecific origin of "North Indian" and "Chinese" sugarcanes. Chromosome Research 10:253-262.

Glaszmann, J.C., A. Fautret, J.L. Noyer, P. Feldmann \& C. Lanaud. 1989. Biochemical genetic markers in sugarcane. Theoretical and Applied Genetics 78:537-543.

Glaszmann, J.C., Y.H. Lu \& C. Lanaud. 1990. Variation of nuclear ribosomal DNA in sugarcane. Journal of Genetics \& Breeding 44:191-198.

Grassl, C.O. 1964. Problems relative to the origin and evolution of wild and cultivated Saccharum. Indian Journal of Sugarcane Research and Development 8:106-116.

Henty, E.E. 1969. A manual of the grasses of New Guinea. Botany Bulletin no 1, Department of Forests, New Guinea.

Hewitt, G. 2000. The genetic legacy of the quaternary ice ages. Nature 405:907-913.

Jannoo, N., L. Grivet, M. Seguin, F. Paulet, R. Domaingue, P.S. Rao, A. Dookun, A. D'Hont \& J.C. Glaszmann. 1999. Molecular investigation of the genetic base of sugarcane cultivars. Theoretical and Applied Genetics 99:171-184. 


\section{Grivet et al. - A Review of Recent Molecular Genetics Evidence for Sugarcane Evolution and Domestication}

Lebot, V. 1999. Biomolecular evidence for plant domestication in Sahul. Genetic Resources and Crop Evolution 46:619-628.

Lu, Y.H., A. D'Hont, D.I.T. Walker, P.S. Rao, P. Feldmann \& J.C. Glaszmann. 1994. Relationships among ancestral species of sugarcane revealed with RFLP using single copy maize nuclear probes. Euphytica 78:7-18.

Mukherjee, S.K. 1957. Origin and distribution of Saccharum. Botanical Gazette 19:55- 61.

Paijmans, K. 1976. Vegetation. Pp 37-97 in New Guinea Vegetation. Edited by K. Paijmans. Australian National University Press, Camberra.

Panje, R.R. 1953. Studies in Saccharum spontaneum and allied grasses 3. Recent exploration for Saccharum spontaneum and related grasses in India. Proceedings of the International Society of Sugar Cane Technologists 8:491-504.

Panje, R.R. \& C.N. Babu. 1960. Studies in Saccharum spontaneum; distribution and geographical association of chromosome numbers. Cytologia 25:152-172.

Piperidis, G., M.J. Christopher, B.J. Carroll, N. Berding \& A. D'Hont. 2000. Molecular contribution to selection of intergeneric hybrids between sugarcane and the wild species Erianthus arundinaceus. Genome 43:10331037.

Sobral, B.W.S., D.P. Braga, E.S. Lahood \& P. Keim. 1994. Phylogenetic analysis of chloroplast restriction enzyme site mutations in the Saccharinae Griseb. Subtribe of the Andropogoneae Dumort. Tribe. Theoretical and Applied Genetics 87:843-853.

Stevenson, G.C. 1965. Genetics and Breeding of Sugar Cane. Longmans, London.

Williams, C. A., J. B. Harborne \& P. Smith. 1974. The taxonomic significance of leaf flavonoids in Saccharum and related genera. Phytochemestry 13:1141-1149. 